\title{
Enabling people to 'see what they can be' The Community Aspirations Program (CAP-ED)
}

\begin{tabular}{c|c}
$\begin{array}{c}\text { Bronwyn Fredericks } \\
\text { Central Queensland University } \\
\text { b.fredericks@cqu.edu.au }\end{array}$ & $\begin{array}{c}\text { Tasha Lamey } \\
\text { Marina Mikecz }\end{array}$ \\
\hline Central Queensland University \\
t.lamey@cqu.edu.au
\end{tabular}

Keywords: aspiration building, cultural identity, enabling education, student experience, participation.

\section{Introduction}

Tertiary education has traditionally been accessible to only the wealthier sections of society, despite a worldwide effort to expand access for people described as disadvantaged. Increasing tertiary education access for minority groups and/or people seen as disadvantaged is just and equitable, as it opens new opportunities to social groups that would not otherwise participate in higher education (Salmi \& Bassett, 2012). In this context, equity can be defined as:

"providing equal opportunities for access and success in tertiary education. It means that circumstances beyond an individual's control, such as birth place, gender, ethnicity, religion, language, disability, or parental income should not influence a person's access to tertiary education opportunities and ability to take advantage of them" (Salmi \& Bassett, 2012, p. 9).

Despite a worldwide push for equitable and inclusive universities, most people who access tertiary education come from wealthy families or have a history of tertiary education in their family. In addition, most tertiary students have parental economic support (Elman \& O'Rand, 2004). Several organisations have highlighted the ongoing issues of poor enrolment rates among people with low socio-economic status (SES), in developing countries and in OECD Countries (for example, World Bank, 2009 and OECD, 2006 in Salmi \& Basset, 2012).

In many countries, race, ethnicity and gender remain obstacles to higher education access. The same obstacles may limit job opportunities and restrict access to well-paid jobs. According to Johnson-Bailey and Cervero (1998), being born White in the United States means being able to access all possible opportunities, while being from a minority group (such as Native American, Latino and African American) means experiencing inequality in education and lack of opportunity. The education system operates primarily in favour of the dominant culture and does no cater fully for the diversity of peoples.

This paper focuses on educational disparity faced by Indigenous Australians. It describes a tertiary access program - called the Community Aspirations Program in Education (CAPED) - developed by the Office of Indigenous Engagement at Central Queensland University 
(CQUniversity). The program was designed to build the educational aspirations of Indigenous people by taking the university to the community and offering opportunities for people to visit the university. It included short learning sessions designed to introduce potential students to the possibility of tertiary study and provide a pathway into an enabling program for university entrance. CAP-ED is designed to inspire and enable Indigenous people - to help them 'see what they can be' and inspire their aspirations to engage in higher education (Devlin, 2013; Oliver, Rochecouste \& Grote, 2013; Oliver, et al., 2013; Pechenkina \& Anderson, 2011; Wilks \& Wilson, 2014).

\section{Education disparity in Australia}

In Australia, the disparity in education access is most apparent in the take-up of education by Indigenous Australians and the delivery of programs to them (Malin \& Maidment, 2003). Australia's historical, cultural and racial contexts combine with the effects of colonisation and previous government policies to impact on the participation of Indigenous Australians in education. In addition, there has been little work to develop and implement broad programs that relate to or are grounded in the identities of Indigenous Australians (Fredericks, et al., 2015; Nakata, et al., 2008; Purdie, et al., 2011; Turnbull 2014; Wilks \& Wilson, 2014),

ABS (2008) data show that, in 2006, the proportion of Indigenous people holding a highereducation qualification (from Certificate I and II to post-graduate degrees) was $29.4 \%$, compared with $54.5 \%$ of the non-Indigenous population. Despite this clear disparity, the data show a marked increase in the proportion of Indigenous people achieving a qualification, particularly at the level of Certificate or Advanced Diploma. In 1996, just $12 \%$ of Indigenous Australians held a Certificate or Advanced Diploma qualification, and this had risen to $23 \%$ in 2006. The proportion of Indigenous people achieving a Bachelor's degree or higher was relatively small, particularly compared to the non-Indigenous population. But this figure also showed great improvement, doubling in 10 years from 3\% in 1996 to $6 \%$ in 2006. Most of the increased qualifications were for Indigenous Australians in major cities or inner regional areas, which also parallels the growth of the Indigenous population in urban and peri-urban areas (ABS, 2008).

In 2011 (ABS, 2013), the gap in education attainment was particularly wide in the 15-24 years age group; only $4.9 \%$ of Indigenous Australians in this age group were attending a higher education institution, compared with $21 \%$ of non-Indigenous Australians. However, even with this large gap, the data show an improvement: between 2006 and 2011, the proportion of Indigenous Australians aged 15-24 enrolled in higher education increased by $63 \%$. In contrast, the data relating to adult education reflects only a small gap. In 2011, 2.6\% of Indigenous Australians aged between 25-64 were enrolled in higher education, compared with 3.6\% of non-Indigenous Australians in the same age group (ABS, 2013). The explanation for this data shift is currently unknown, and warrants further research. What is clear, though, is that younger Indigenous Australians access higher education at lower rates than non-Indigenous Australians: Indigenous Australians are missing out on education at the point when many Australians are accessing higher education to establish their careers (Oliver, Rochecouste \& Grote, 2013; Oliver, et al., 2013; Pechenkina \& Anderson, 2011).

The ABS data $(2008 ; 2013)$ demonstrate that, while education access for Indigenous Australians is improving, more needs to be done to narrow the gap. Access to higher education offers important benefits, both at a personal level and a societal level (Salmi \& Bassett, 2012; Wienclaw, 2009). The data demonstrate that higher education can be accessed throughout life; early school leavers may choose to return to education to increase their employment prospects, improve their social status and earn more money (Wienclaw, 2009), or simply to improve their education level. 
For many adult learners, education is a way to increase their knowledge and provide options in their career (including career development or career change). Socially, there are a number of benefits in expanding access to higher education to the wider community, including financial benefits (reduced unemployment, higher tax revenues), higher community involvement, improved health outcomes and decreased dependence on government help. The number of people living below the poverty line decreases in line with an increase in education attainment (Swail, 2003). The Review of Higher Education Access and Outcomes for Aboriginal and Torres Strait Islander People (Behrendt, Larkin, Griew \& Kelly, 2012) states that higher education and training are important and powerful tools, not just to empower Indigenous communities and improve their socio-economic status, but also for Australia's socio-economic development more broadly. The 'transformative processes' offered by education are consistent with the commitment to address Indigenous disadvantage as a central goal of the Closing the Gap agenda (Behrendt, et al., 2012, p. 3).

For marginalised and under-represented peoples, accessing higher education presents a variety of financial, personal and academic obstacles. Many people are not ready to study at tertiary level due to poor academic success in $\mathrm{K}-12$ schooling. They may be aware that tertiary study requires organisational skills and a commitment of both time and money - all of which can be challenging. In addition, marginalised and under-represented people may feel no sense of belonging or connection with tertiary education - it can be seen something that is intended for others and is not welcoming to them.

Tertiary institutions and governments seek to address these obstacles through policies and programs designed to increase people's readiness for higher education. Bridging and outreach programs, for example, are designed to reduce financial and academic obstacles. However, it is difficult to monitor the success of these programs (Salmi \& Bassett, 2012). In addition, they are typically designed to 'welcome students in' to study at the institution, rather than 'take the institution out' to where potential students might be.

\section{Developing a localised, Indigenous program}

The Office of Indigenous Engagement at CQUniversity wanted to develop a short, informal, local learning program that would challenge, encourage and inspire Indigenous people to begin an educational journey. The vision of the program was to offer activities and learning projects to introduce university study as a feasible option for people.

CQUniversity began the Community Aspirations Program in Education, known as CAP-ED, in 2013. The program's goal was to increase Indigenous student participation in higher education and to build their aspirations through small, manageable learning sessions or projects. Initially, the CAP-ED team proposed to develop and deliver an accredited certificate program, which would facilitate access to a university enabling program (or direct entrance to university). The team explored existing, accredited programs that could be suitable for implementation at CQUniversity, and considered options for developing a new program.

The CAP-ED team were conscious that the Central Queensland region has no specific literacy, numeracy or English-as-a-second-language programs for local Indigenous people. They felt that developing a local program to address this issue may assist in developing educational access paths for Indigenous students, particularly by helping potential students to transition into university enabling programs and on to undergraduate studies. This is supported by research undertaken by Behrendt et al. (2012) who noted that, in 2010, over half of Indigenous students entering university did so through an enabling program, compared with only $17 \%$ of non-Indigenous students. While CQUniversity had two enabling programs in 2013 , it did 
not have an Indigenous-specific course or a program to facilitate and support people into the enabling programs.

The CAP-ED team identified several programs operating at other universities and training organisations that had potential application for CQUniversity. A Victorian VET-based program looked particularly promising. However, further investigation of the course and local community consultation showed that importing a program from another institution was not going to work for the local community. While an excellent program for Victorian communities as the program was included Aboriginal concepts, language and imagery from Victorian regional communities, it contained little reference to coastal communities, designated Aboriginal communities (past reserves) or include references to Torres Strait Islander peoples. The copyright held with the program and Victorian registration of it meant that there was little opportunity for adaption or amendment. In our continued exploratory work, there were few programs available that could be adapted or amended for our project's purposes within Central Queensland. What became apparent was that CQUniversity needed to develop a localised program, designed specifically for Indigenous people in Central Queensland. It was also clear that we would not be able to develop an affordable or free certificate course that would meet community needs and also attract a government fee subsidy.

The CAP-Ed team implemented a process of deeper consultation with six communities in the CQUniversity footprint, including one designated Indigenous community and five rural/regional communities. The consultation included extensive consultation with Traditional Owners, Elders, community members and key stakeholders, followed by a process of engagement with communities to develop partnerships and an appropriate outcome. These types of partnerships are written documented in the literature (See Hoffman, et al., 2012; National Congress of Australia's First Peoples, 2012; Taylor \& Thompson, 2011)

The community engagement was carefully conducted to be two-way and respectful. The CAPED team needed to seek and receive views from individuals and communities about what might work best, not simply 'tell' the communities what the university could offer. This early phase was important in terms of developing relationships and sharing understandings of what might be needed. It set the tone for later decision making in the program-development phase, agreeing about what would happen in each community, and talking about who would do what. Through close engagement with communities, the CAP-ED team developed partnerships for the program design and delivery, and developed an understanding of the strengths and needs of each community.

Detailed notes were kept of all the consultation and engagement activities and the CAP-ED team developed profiles for each community to assist in working with each community. This information was locked in stored filing cabinets. The multiple ways of collecting information was shared with the communities and agreement was reached on what would be documented. This also developed interest from community members as to how the team worked and developed an interest in wanting to assist in documentation to ensure the team got it right. The CAPED team has undertaken a short video on the work featuring participants, which generated lots of interest and a desire to undertake more multi-media work with not only the CAP-ED team but also the Office of Indigenous Engagement. CQUniversity Talent Release forms were filled out for participants, stakeholders, Elders and other persons. CQUniversity undertakes a lot of digital media work and is a big user of social media and the images were used for these purposes too. As the program developed community members would ask if the team was taking their picture and would pose in readiness, which created a sense of fun. All the communities responded in a positive way, which allowed for a deepening of the relationships between team members as individuals and as a team and the communities. 
For the CAP-ED team, developing a deeper knowledge of the six Central Queensland communities was vital for understanding people's attitudes, recognising cultural protocols, and identifying the appropriate ways to bring people together to share information, work on problems and find solutions. The team was eager to ensure that community members were engaged in all phases of developing the program. They worked to involve the community in generating knowledge and planning how the knowledge would be used. In addition, community members were involved in planning for educational change within their community, as they considered how the new CAP-ED program might change the education trajectory of their community members.

The six communities share some common beliefs and practices. But each community is unique and has evolved to have its own local knowledge and customs. The CAP-ED team worked from an understanding that local knowledge plays an important role in keeping people and places together and in co-creating new forms of togetherness. The team aimed to build on community practices, rather than impose an external way of working - approaching the project as 'working with' not 'working for' the local communities. This close engagement helped to embed Indigenous cultures into the program as it was developed.

\section{The CAP-ED suite of activities}

The CAP-ED program that emerged from the community consultation is a short, achievable, five-week course called CQU and Me. It is offered as a series of short workshops, and aims to develop the aspiration of Indigenous people to enrol in university. The program responded to the communities' desire for a series of networking and information events that focused on sharing and open communication between participants and guest speakers, with guest speakers sharing their stories of success.

\section{CQU and Me five-week format}

The format of CQU and Me varies slightly, depending on the individual needs and interests of local communities. The Rockhampton program (Fig. 1) was delivered over five weeks. 
Figure 1: CQU and Me

Week 1 Introduction

- Program overview.

- Getting to know each other.

- What are your dreams and aspirations?

- University - it's not a scary place!

- How it all works, what can I study?

Week 2 Cultural Connections

- Cultural information session (Traditional Owners deliver these sessions).

- Indigenous games.

Week 3 Study at University

- Visit to schools (such as allied health, nursing, physiotherapy and paramedic).

- Sports Centre tour.

- Library tour.

Week 4 Professionals in the Workplace

- Meet Indigenous professionals in their workplace (such as Glenmore State High School, Bidgerdii Community Health Service, Queensland Health and Queensland Ambulance).

Week 5 Artistic creation

- Produce film reflecting on the journey participants have taken over the previous weeks.

\section{Networking lunches}

In some communities, the five-week CQU and Me program was held in conjunction with a networking lunch, which featured two guest speakers who shared their learning journey and reflected on the importance of tertiary education. The idea for networking lunches grew from the community consultations, where people talked about the need for Indigenous people to hear from other Indigenous people who had successfully navigated different education pathways that had led them to personal or professional success.

The networking lunches were held either on a CQUniversity campus or at suitable venues in the community. They were highly successful, attracting between 10 and 60 people depending on the location. The lunches helped to engage with the wider community (beyond the program participants) and encouraged the community to support participants as they progressed through the CQU and Me program. Importantly, the lunches were appealing for both people who were employed and had not considered higher education, and for people who were seeking a career change. They offered an affirmation for the community and opened up awareness about the possible achievements that can be gained through education. For example, one woman who had been working in an entry-level (ASO3) position for over 10 years was motivated to consider higher education as a pathway for career progression. Another woman who worked as a service station attendant said she was 'held back' because she didn't have an education. 
The networking lunches became an important addition to the CQU and Me program. They enabled people to listen, be inspired, dream and explore possibilities. They enabled people to 'see what they can be' and helped to build Indigenous aspirations for higher education.

\section{Information sessions}

CQU and Me began with local information sessions designed to offer a no-fuss, sharing of information about people and services available to support Indigenous people in education (such as Registered Training Organisations, schools, youth programs and others). The information sessions are designed to be delivered in any location, with or without audio-visual support. Their purpose is to encourage discussions about possible education pathways and provide an entrance into the five-week CQU and Me program. They enable people to think about what might be possible and then to take a step on their own journey or support others to begin an educational journey.

\section{Program feedback}

CQU and $M e$ is tailor-made for each community, to reflect participant needs, utilise local knowledge and expertise, and be delivered in collaboration with community organisations. Feedback from participants includes:

"I knew about the University but didn't know how to get the information of what I wanted to study and how to enrol." Adam

"I have had such a great time and don't want the program to end." Marg

"When I started the program I wasn't too confident within myself but now I have had this experience I am looking at studying the Bachelor of Nursing and Midwifery." Suzi

"I never learnt or don't remember this cultural information taught at school and [it] has given me more insight on Aboriginal and Torres Strait Islander issues around alcohol and drug use, domestic violence and crime etc." Sue

"Had such a great experience at the Mackay Campus. Can we have another session with other schools?" John

"Partnerships with local Aboriginal and Torres Strait Islander Elders and respected people in the communities have also enhanced the program." Nathan

Flexibility is an important aspect of the program's success, with the program's session format, times and topics all being chosen to suit the needs of participants and presenters. Sessions can be shortened, lengthened or adapted in response to the needs of the local community. This was reflected in some communities, where the program was reduced from five weeks to three weeks.

In all six communities, the CAP-ED team witnessed a great deal of engagement with people as partners in the program's delivery and co-presenters in sessions and other events. The focus on local identity, culture and aspirations was extremely valuable in building local ownership and engagement. It provided a platform for people to ask questions, voice honest concerns, build their confidence and begin to 'see what they can be'. 


\section{Lessons learned}

The CAP-ED program was designed to build capacity and inspire Indigenous people to think about higher education as a real possibility. It focused on encouraging people to 'see what they can be'. In this way, it aimed to encourage people to become role models for future family members, gain respect from the Indigenous community, take a step to build a better future and career pathway, reconnect with their Indigenous culture, develop skills for employment, and transition into undergraduate studies or university enabling programs (such as the Tertiary Entry Program (TEP) and Skills for Tertiary Education Preparatory Studies (STEPS).

The success of the CAP-ED program as implemented through the CQU and Me workshops rested on its close connection with Elders and Traditional Owners in each community, who provided a vital link to participants. The project team took the time to develop, maintain and sustain relationships with community members and service providers, and this paid off in their trust and support for the program as it was implemented. Communities were initially hesitant to engage with the project. However, as soon as the project employed Indigenous staff who were connected with the communities and had local knowledge, community engagement became much easier. Early engagement fostered additional engagement as the team developed greater local knowledge and opened dialogue between the communities and the university. While it can be challenging to build into projects opportunities for discussion and deep engagement, the efforts pay off through greater opportunities for development, empowerment and change. By developing deep relationships with Elders and community members, the CAP-ED team designed a program with community ownership of both the process and the outcomes.

An important aspect of the program includes its flexible delivery, which accommodates the varying needs and priorities of each community and recognises differences in cultural protocols and community approaches. Face-to-face engagement between community members and knowledgeable, skilled staff was vital. Through close engagement with six different communities, CAP-ED developed into a broad strategy that can successfully match community needs and university responses.

The CAP-ED program has provided CQUniversity's Office of Indigenous Engagement with a deeper connection to Indigenous communities in the university's footprint and enabled us to be more responsive to community needs. In this way, it has inspired and empowered staff through a process of reciprocity and benefit for all involved. The CAP-ED program has supported the Office of Indigenous Engagement to further develop learning environments and opportunities that build on strengths, develop capacity and honour Indigeneity. We have implemented processes of documentation, monitoring and review to help us to continually reflect on and adapt the program. Most importantly, the CAP-ED program has offered local Indigenous people with an option and pathway into higher education where no options previously existed. We believe that CAP-ED will encourage more Indigenous people to access higher education and lead to increased positive outcomes long after they have finished the short CQU and Me program. It offers an opportunity for Indigenous Australians to 'see what they can be' (Wilks \& Wilson, 2014) and to take a concrete step towards being what they see.

\section{Acknowledgements}

We acknowledge the contributions to the CAP-ED program made by the participants, Elders and community members along with Malcolm Jarrett and other CQUniversity staff. You have all contributed to making the CAP-ED program what it is today. 


\section{References}

ABS (Australian Bureau of Statistics). (2008). Australian social trends 2006 (Cat. No. 4102.0). Canberra: Author. Retrieved 13 July 2015 from http://www.abs.gov.au.

ABS (Australian Bureau of Statistics). (2013). Australian social trends 2011 (Cat. No. 4102.0). Retrieved 13 July 2015 from http://www.abs.gov.au.

Behrendt, L., Larkin, S., Griew, R., \& Kelly, P. (2012). Review of higher education access and outcomes for Aboriginal and Torres Strait Islander people, final report. Retrieved from http://www.innovation. gov.au/highereducation/IndigenousHigherEducation/ReviewOfIndigenousHigherEducation/ FinalReport/IHERFinalReport.pdf.

Devlin, M. (2013). Effective university leadership and management of learning and teaching in a widening participation context: Findings from two national Australian studies. Tertiary Education and Management, 19(3), 233-245. DOI: 10.1080/13583883.2013.793380

Elman, C., \& O'Rand, A.M. (2004). The race is to the swift: Socioeconomic origins, adult education, and wage attainment. American Journal of Sociology, 110(1), 123-160.

Fredericks, B., Mann, J., Skinner, R., Croft-Warcon, P., McFarlane, B., \& Creamer, S. (2015). Enabling Indigenous education success beyond regional borders. Journal of Economic and Social Policy, 17(2), Article 3. Retrieved from http://epubs.scu.edu.au/jesp/vol17/iss2/3.

Hoffman, B., Roeger, S., Wise, P., Dermer, J. Yunupingu, B., Lacey, D., Yunipingu, D., Marika, B., Marika, M. \& Panton, B. (2012). Achieving highly successful multiple agency collaborations in a crosscultural environment: experience and lessons from Dhimurru Aboriginal Corporation and partners. Ecological Management \& Restoration, 13(1), 42-50.

Johnson-Bailey, J. \& Cervero, R.M. (1998). Postcoloniality: Whiteness as a social construct that drives classroom dynamics. Proceedings of the $39^{\text {th }}$ Annual Adult Education research Conference (pp. 203-208). San Antonio, Texas: University of the Incarnate World College.

Malin, M., \& Maidment, D. (2003). Education, Indigenous survival and well-being: Emerging ideas and programs. Australian Journal of Indigenous Education, 32, 85-99.

Nakata, M. Nakata, V. \& Chin, M. (2008), Approaches to the academic preparation and support of Australian Indigenous students for tertiary studies. Australian Journal of Indigenous Education, 37S, 137-145.

National Congress of Australia's First Peoples. (2012). Engagement Framework: a Framework for engagement between Australian Government agencies and the National Congress of Australia's First Peoples. Sydney, Australia: National Congress of Australia's First Peoples.

Oliver, R., Rochecouste, J., \& Grote, E. (2013). The transition of Aboriginal and Torres Strait Islander students into higher education. Sydney, Australia: Office for Learning and Teaching, NSW Department of Education.

Oliver, R., Rochecouste, J., Bennell, D., Anderson, R., Cooper, I., Forrest, S., \& Exell, M. (2013). Understanding Australian Aboriginal tertiary student needs. International Journal of Higher Education, 2(4), 52.

Pechenkina, E., \& Anderson, I. (2011), Background paper on Indigenous Australian higher education: Trends, initiatives and policy implications. Canberra, Australia: Department of Education, Employment and Workplace Relations.

Purdie, N., Milgate, G., \& Bell, H.R. (2011). Two way teaching and learning: Toward culturally reflective and relevant education. Camberwell, Australia: ACER Press. 
Salmi, J.I., \& Bassett, R.M. (2012). Opportunities for all? The equity challenge in tertiary Education. Washington DC: The World Bank. Viewed 15 July 2015, http://www.salzburgglobal.org/fileadmin/ user_upload/Documents/2010_2019/2012/495/Session_Document_OpportunitiesforAll_495.pdf.

Swail, W.S., with Redd, K.E., \& Perna, L.W. (2003). Retaining minority students in higher education: A framework for success (ASHE-ERIC Higher Education Report, Volume 30, No 2). San Francisco, CA: Jossey-Bass Higher and Adult Education Series.

Taylor, K. \& Thompson, S. (2011). Closing the (service) gap: exploring partnerships between Aboriginal and mainstream health services. Australian Health Review, 35, 297-308.

Turnbull, M. (2014). Creating an accessible and effective pathway for regional and isolated Aboriginal and Torres Strait Islander people to tertiary study using block-release study mode. Sydney, Australia: Office for Learning and Teaching, New South Wales Department of Education.

Wienclaw, R.A. (2009). Adult education as social capital. Research Starters Sociology (Online Edition), EBSCOhost. Retrieved 1 July 2015 from http://www.academicpub.com/map/items/29602.html.

Wilks, J.L., \& Wilson, K. (2014). 'Can't be what you can't see': The transition of Aboriginal and Torres Strait Islander students into higher education. Literature Review 2014. Broome, Australia: University of Notre Dame Australia. Retrieved from http://www.nd.edu.au/_data/assets/pdf_ file/0018/122364/OLT-ID-SI11-2138-Lit-Rev-Final-14-March-2014.pdf.

Williams, G. (Ed). (2011). Talking Back, Talking Forward. Journeys in Transforming Indigenous Education Practice. Darwin, Australia: Charles Darwin University. 